\title{
LEXICALIZACIÓN DIMINUTIVA EN DOS CORPUS ORIGINALES (LENGUA ORAL Y LENGUA ESCRITA)
}

\author{
DIMINUTIVE LEXICALIZATION IN TWO ORIGINAL CORPORA \\ (ORAL LANGUAGE AND WRITTEN LANGUAGE)
}

\author{
Cecilia CRiado de Diego \\ ceciliacriado@flog.uned.es \\ María Antonieta Andión Herrero \\ maandion@flog.uned.es \\ Universidad Nacional de Educación a Distancia
}

Enviado: 22/08/2018

Aceptado: 05/10/2018

\begin{abstract}
Resumen
A través de dos corpus originales, estudiamos el comportamiento de las palabras lexicalizadas con diminutivo en la lengua española actual, escrita y oral. Una vez localizados y anotados estos términos, atendemos principalmente a tres aspectos: fecha de registro en los diccionarios y corpus académicos, semántica en relación con la palabra base y procedencia geolectal. Constatamos que el fenómeno muestra vitalidad como recurso panhispánico; asimismo, observamos un tratamiento desigual de estas palabras en los diccionarios académicos y una presencia mayoritaria del fenómeno en el español europeo en los dos corpus originales.

PALABRAS CLAVE: diminutivos, lexicalización, variedades del español, corpus oral, corpus escrito.
\end{abstract}

\begin{abstract}
Through two original corpora, we study the behaviour of diminutive lexicalization in present day written and oral Spanish. Once these terms are located and annotated, we mainly deal with three aspects: date of registration in dictionaries and academic corpora, meaning in relation to the root word and geolectal origin. We find that the phenomenon shows vitality as a Pan-Hispanic resource; we also observe that the treatment of lexicalized words in Spanish general language dictionaries tends to vary. Finally, we find that European Spanish uses lexicalized diminutives more often in both corpuses, oral and written, than American Spanish.

KEYWORDS: diminutives, lexicalization, varieties of Spanish, oral corpus, written corpus.
\end{abstract}

\section{INTRODUCCIÓN}

La lexicalización o el proceso mediante el cual un "elemento lingüístico pasa a formar parte del sistema léxico de una lengua" (Diccionario de la lengua española, a partir de ahora $D L E$ ) o un "elemento léxico se hace más léxico" (Brinton y Traugott 2005; Bue-

Para citar este artículo / To cite this article: Criado de Diego, Cecilia y María Antonieta Andión (2018). Lexicalización diminutiva en dos corpus originales (lengua oral y lengua escrita). ELUA, 32: 73-90. doi: 10.14198/ELUA2018.32.3

Enlace / Link: http://dx.doi.org/10.14198/ELUA2018.32.3 
nafuentes y Sánchez 2012; Elvira 2006) puede relacionarse con los cambios lingüísticos vitales de una lengua y con esa peculiar apreciación de su comunidad de hablantes, que evoluciona con el propio desarrollo de la sociedad y adapta sus formas expresivas.

En el caso del español, este proceso de cambio ha actuado en numerosas palabras cuyos sufijos fueron, en un principio, un recurso gramatical para expresar apreciación. El repetido uso del vocablo, la comprensible falta de conciencia etimológica de los hablantes o sus preferencias y creatividad lingüísticas -esperable en una lengua viva y tan extensa como el español- pudieron ser las causas del cambio desde lo gramatical hacia lo léxico. Así se ha ido generando un caudal de palabras opacas, no transparentes o lexicalizadas, que se distinguen de las transparentes porque su significado no "se obtiene de la combinación de la base y el sufijo", sino que "forman parte del repertorio léxico del idioma" (RAE y ASALE 2009: 635). Por ejemplo, la acepción que tiene vinillo en algunas variedades hispanas, "vino muy flojo', no puede inferirse "combinatoriamente", por lo que está incluido en el $D L E^{l}$. Sin embargo, este diccionario excluye vinito porque es una formación a cuyo significado llegamos siguiendo las reglas productivas de derivación y añadiendo a la palabra vino los matices semánticos propios de los diminutivos (RAE y ASALE 2009: 636).

A pesar del interés y actualidad del tema, la lexicalización, opacidad o desgramaticalización ${ }^{2}$ diminutiva cuenta con poco desarrollo teórico y sus estudios suelen estar inmersos en los que tratan la gramaticalización (Buenafuentes y Sánchez 2012: 155). No obstante, algunos autores como Monge (1965 [1962]), Lázaro (1999) o Montero (2008) le dedican atención y coinciden con la RAE y ASALE al definir el proceso como el resultado de la pérdida de las "significaciones primarias" (Montero 2008: 118) del diminutivo, ya sean exclusivamente connotativas (Lázaro 1999: 4650; Monge 1965: 139 y ss.) o connotativas y aminorativas (Montero 2008: 118).

La dificultad que entraña determinar si este proceso de pérdida ha sido o no culminado, además de otras cuestiones como la posibilidad de incluir en el repertorio léxico palabras con diminutivo que no han perdido sus significaciones denotativas de disminución, ha provocado un tratamiento desigual de estas palabras en los diccionarios generales de nuestra lengua. En este estudio, nos proponemos analizar este y otros aspectos del fenómeno en los diminutivos para conocer cuál es su estado y comportamiento en la lengua escrita y oral actual a través de un corpus original, cuyos resultados muestran su vitalidad como recurso léxico panhispánico.

\section{DESCRIPCIÓN DE DOS CORPUS ORIGINALES PARA EL ESTUDIO DE LA LEXICALIZACIÓN DIMINUTIVA}

Con la intención de contribuir al estudio de la lexicalización diminutiva e inferir conclusiones que no se limitaran a deducciones introspectivas, hemos utilizado no solo fuentes como obras descriptivas y prescriptivas de la lengua, sino también corpus pues estos aportan una información auténtica y veraz de uso en hablantes reales (Kock 2001; Pérez Hernández 2002; Sánchez et alii $1995^{3}$ ).

1 La RAE y la ASALE se refieren en sus citas al DRAE (Diccionario de la Real Academia Española), y no al $D L E$, puesto que en el 2009 aún no estaba publicada esta última edición del diccionario.

2 Carlos Sánchez Lancis (2015: 14) utiliza esta denominación.

3 Además de los autores citados, como Kock, que se centra en las aplicaciones sobre el español, remitimos a los estudios de Kennedy (1998), entre otros, para argumentar la relevancia de los estudios de corpus para la Lingüística. 
Para ello, recopilamos, observamos y analizamos un corpus lingüístico especializado propio $^{4}$, una muestra oral y escrita empírica y significativa que responde a nuestros objetivos e intenciones antes declarados, además de dos tipos de discurso: los textos periodísticos de opinión y los programas de cocina. En adelante nos referiremos a este corpus como Corp-LO/LE.

La representatividad del Corp-LO/LE está determinada, por tanto, más que por la diversidad de géneros (artículos de prensa y programas de cocina) y registros (culto o semiculto en situaciones de formalidad o semiformalidad), por la inclusión de "palabras procedentes de todos y cada uno de los territorios en los que se habla [español] en la misma proporción en la que se distribuyen los hablantes" (Cruz Piñol 2012: 37). Estos materiales constituyen un corpus simple o bruto, ya que no están lematizados. Nuestro objetivo fue únicamente "consultar ocurrencias y concordancias de una palabra en una realización concreta” (Ibídem: 53).

Asimismo, el Corp-LO/LE fue compilado reuniendo en un único archivo los enlaces a internet de los artículos y los programas seleccionados (consultar notas 5 y 6). El corpus escrito (Corp-LE) está constituido por 970 artículos de prensa (170 de la zona española, 163 de la mexicana y centroamericana, 170 de la caribeña, 157 de la andina, 160 de la chilena, 160 de la rioplatense) escritos por cien informantes (53 hombres y 47 mujeres) nacidos entre 1925 y 1986. Todos los artículos son de opinión y versan sobre temas diversos, desde el análisis de la realidad política y socioeconómica, nacional e internacional, hasta artículos de arte, literatura e historia, o también, psicología, deportes o entretenimiento ${ }^{5}$.

El corpus oral (Corp-LO) está formado por seis horas y media de grabaciones de programas multimedia de cocina (58 minutos de la zona española, 47 de la mexicana y centroamericana, 65 de la caribeña, 85 de la andina, 49 de la chilena, 78 de la rioplatense) donde participan 44 informantes nacidos entre 1925 y 1985. Los programas son grabaciones de los últimos treinta años -la mayoría, de los últimos diez- y constituyen programas de cocina para la televisión o el canal Youtube en forma monologada o dialogada. Todos ellos presentan informantes que hablan de una forma espontánea o con un guion flexible ${ }^{6}$.

Un aspecto importante y de interés para la formación del Corp-LO/LE fue atender especialmente a la presencia de la variedad geolectal del español. Las muestras que lo conforman representan proporcionalmente tanto la escritura y la oralidad como las diferentes áreas geolectales. Aunque no realizaríamos un análisis dialectológico exhaustivo sino un estudio general del proceso de lexicalización diminutiva, sí pretendíamos encontrar referencias de todo el mundo hispánico. Esta abarcadora dimensión hacía improcedente, por tanto, subdividir dialectalmente España (a pesar de su evidente variedad) cuando en la zonificación geolectal americana, sus diecinueve países se estructuraban en cinco zonas según la aceptada clasificación de Henríquez Ureña (1921: 39-62).

4 Lo consideramos un corpus especializado - es decir, no de referencia- porque recoge un tipo de lengua, responde a nuestros objetivos de estudio y tiene una representatividad dialectal controlada (Navarro 2008).

5 Estos artículos fueron consultados en internet entre los días 7 de noviembre de 2013 y 25 de mayo de 2014. La información relativa a este corpus (datos sobre los informantes, título y fecha de publicación de los artículos) puede consultarse en internet en este enlace: www.goo.gl/2CF6jC.

6 Los vídeos fueron consultados entre el 1 de junio y el 20 de diciembre de 2014. La información relativa a este corpus (datos sobre los informantes y enlaces a los vídeos) puede consultarse en internet en esta dirección: www.goo.gl/QNaJQA. 
Utilizamos, entonces, la siguiente clasificación de las variedades geolectales: (1) variedad española: España; (2) variedad mexicana y centroamericana: regiones bilingües del Sur y Sudoeste de los Estados Unidos de América, México y las repúblicas de América central; (3) variedad caribeña: Cuba, Puerto Rico, República Dominicana, la costa y los llanos de Venezuela y la porción occidental de Colombia; (4) variedad andina: región andina de Venezuela, el interior y sur de Colombia, Ecuador, Perú, la mayor parte de Bolivia y el norte de Chile; (5) variedad chilena: la mayor parte de Chile; (6) variedad rioplatense o austral: Argentina, Uruguay, Paraguay y el sudeste de Bolivia.

\section{APUNTES MORFOLÓGICOS SOBRE LOS DIMINUTIVOS LEXICALIZADOS DEL CORP-LO/LE}

Abordar la lexicalización del diminutivo en los corpus condujo, inevitablemente, a que observáramos la diversidad de su morfología, empezando por reflexionar sobre si estas palabras se unían a los lexemas mediante un proceso derivativo (creando un nuevo vocablo), o si, por el contrario, lo hacían mediante un proceso flexivo (alterando la palabra pero sin modificar el significado de su lexema). Sin la intención de ser exhaustivos en el tema, lo que rebasaría con mucho este artículo, partimos de que los diminutivos no suelen implicar cambios de género, número, persona, tiempo, modo o aspecto, funciones a cargo de los morfemas flexivos, por lo que los gramáticos (entre ellos: Bello 1984 [1847]; Marcos Marín y España Ramírez 2001; Nebrija 1492; Seco 1971 [1930]; RAE y ASALE 2009) tienden a incluirlos en los morfemas derivativos. Gómez Torrego (2005 [1997]: 21 y ss.) procede de la misma manera, pero distingue entre sufijos obligatorios de significado no gramatical, que son los que aportan un significado nuevo al concepto que designa la raíz, y los potestativos, que matizan semánticamente lo designado por el lexema desde un punto de vista afectivo o expresivo. A estos últimos pertenecerían los diminutivos junto con los aumentativos, despectivos, superlativos y, lo que este autor denomina, familiares.

El hecho de que en español el diminutivo cambie de forma según el tipo de palabra base a la que se una ha hecho reflexionar a varios autores (Lázaro 1977: 115-125; Martín 2001: 339-351; Spitzer 1921: 58-60; Ponce de León 2006: 51-69) sobre la existencia de interfijos y/o infijos en este proceso derivativo. Si partimos de considerar, como Malkiel (1958), que un interfijo es el segmento átono y falto de significado propio entre el radical y el sufijo de ciertos derivados (humareda), y un infijo se caracteriza por seccionar la raíz convirtiéndola en un morfo discontinuo, -ecito, -ecita estarían formados por el interfijo -ec- y el sufijo -ito, -ita (y también -ecillo, -ecilla, -ecín, -ecina, -ecico, -ecica, etc.), en casos como padrecito o nuevecita, mientras que -cito, -cita lo estarían por el interfijo - $c$ - y el mismo diminutivo, en formas como cafecito o mamacita. De la misma manera, en ejemplos del tipo Carlitos, lejitos o Merceditas, -ito, -ita se formarían a partir de un infijo -it-, mientras que -cito, -cita, en Dolorcitas, por ejemplo, lo harían con el infijo - cit- $^{7}$. De cualquier manera, como señala Lázaro (1999: 4671-4672), la realidad es que la derivación con diminutivos entraña dificultades debidas a razones fonológicas, prosódicas y morfológicas.

7 Las funciones de estos interfijos son evitar el hiato, distinguir homonimias, conservar el acento en la raíz y eliminar secuencias cacofónicas (Malkiel 1958). 
En resumen, los condicionamientos que determinan en general la alomorfia de los diminutivos, como señalan Ambadiang y Bergareche (2013: 182), "siguen siendo los mismos que eran en un principio, pero su modificación parece haberse iniciado ya en algunos dialectos más dinámicos de América" y, en el caso de las palabras con diptongo, también en España. Así, la tendencia en muchas zonas lingüísticas americanas es la supresión del interfijo -ec-, de manera que las palabras base que terminan en -e, junto con aquellas que acaban en $n$ o $r$, seleccionan el diminutivo sin interfijo: dulce-dulcito, hambre-hambrita; mientras, los monosílabos recurrirían al interfijo -c-: pan-pancito, bar-barcito. Según Ambadiang y Bergareche (2013), en la variedad peninsular española, en cambio, las únicas bases léxicas que muestran alternancia son las bisílabas acabadas en vocal temática que contienen diptongo: nuevito/nuevecito, piedrita/piedrecita, lengüita/lengüecita.

Los morfemas que gramáticos como Bello (1984 [1847]), Seco (1971 [1930]), Gómez Torrego (2005 [1997]), Lang (2002), entre otros, han clasificado como propios del diminutivo, y que se han presentado en las palabras lexicalizadas del Corp-LO/LE, son: -ito, -ita (11 de 101, 10,9 \%: señorito); -illo, -illa (66 de 101, 65,3\%: avanzadilla); -ete, -eta (9 de 101, 8,9\%: papeleta); -ino, -ina, -ín (11 de 101, 10,9\%: teresina, camarín); -uño, -uña (1 de 101, 1 \%: terruño); -uelo, -uela (3 de 101, 3 \%: cazuela). Mayoritariamente estos diminutivos utilizan la forma -illo, -illa, que parece haberse especializado en la lexicalización, como advierte Pharies (2002), y como puede verse en el gráfico 1, donde aparecen representadas las palabras lexicalizadas halladas en nuestros corpus, y que parece bastante fiel al comportamiento que, según la bibliografía, tienen estos términos a ambos lados del Atlántico, sobre todo en lo que se refiere a la diferencia entre -illo y el resto de sufijos.

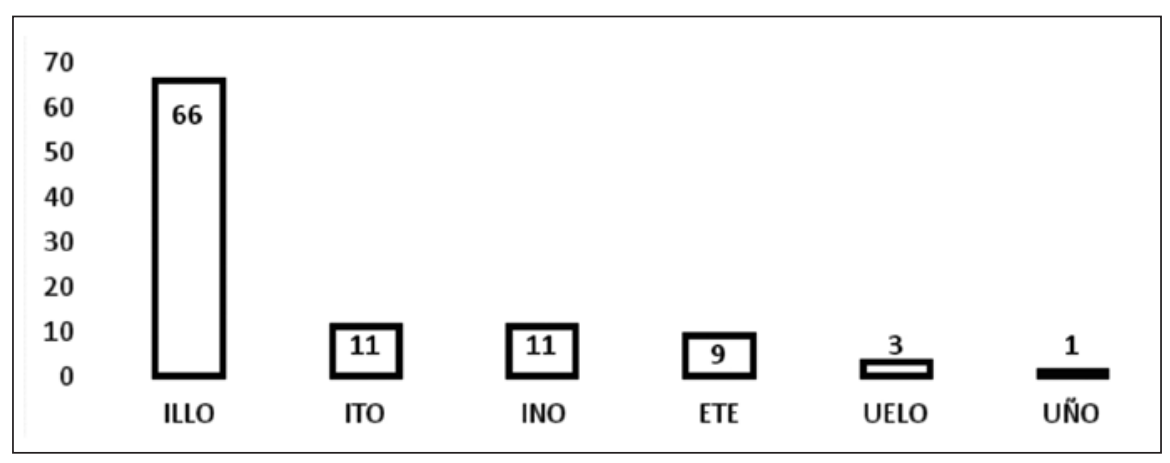

Gráfico 1. Formas diminutivas en palabras lexicalizadas del Corp-LO/LE

\section{SELECCIÓN, REPERTORIO Y CLASIFICACIÓN DE LOS DIMINUTIVOS LEXICALIZADOS}

Ante todo, queremos aclarar que la selección ofrecida en este trabajo depende de la casuística de la muestra por haber utilizado fuentes no manipuladas, reales y auténticas. Tenemos en cuenta que la opacidad o transparencia de un diminutivo es difícilmente objetivable, pues depende de la "conciencia lingüística de los hablantes" (RAE y ASALE 2009: 
636) y que la propia geografía del español propicia que ciertas palabras estén lexicalizadas solo en determinados geolectos. Ello condiciona que, en el repertorio de estas palabras, solo incluyamos las que no tienen una acepción predecible a partir de la palabra base, como juntillas ${ }^{8}, \mathrm{y}$ aquellas en las que el diminutivo no añade nuevos matices significativos aunque mantenga el mismo significado que su derivante (cigarrillo).

Por su parte, no consideramos las palabras cuyo diminutivo enfatiza el aminoramiento de lo referido (poquito, trocito), porque, aunque estos vocablos poseen cierto grado de lexicalización, el proceso no se ha desarrollado lo suficiente como para eliminar por completo las connotaciones propias de los sufijos apreciativos. También aclaramos que en el Corp-LO/LE existen palabras cuyo proceso de lexicalización diminutiva fue heredado por el español y que no hemos considerado aquí de nuestro interés; es el caso de abeja, casino y camioneta. La primera procede del latín apicŭla, diminutivo de apis ('abeja'); por su parte, casino y camioneta (camionette) son igualmente vocablos lexicalizados con diminutivo (del italiano casa y del francés camion, respectivamente) pero su proceso de cambio lingüístico tuvo lugar en sus propias lenguas, no en español. Solo hemos seleccionado aquellas palabras cuyo proceso de lexicalización diminutiva se produjo dentro de la propia historia de la lengua española.

Para corroborar la lexicalización de los diminutivos fue necesario acudir a su étimo. En esta tarea fueron nuestras principales fuentes de consulta el Diccionario crítico y etimológico castellano e hispánico (Corominas y Pascual 1981), de Joan Corominas y José Antonio Pascual, el DLE y el Diccionario de Americanismos (a partir de ahora DicAm). Además, consultamos la fecha del primer registro en el Corpus Diacrónico del Español (CORDE) ${ }^{9}$ en relación con la fecha de entrada en las obras académicas, dato que nos aportó el Nuevo tesoro lexicográfico de la lengua española (RAE y ASALE 2001), que compendia sus diccionarios desde 1495 hasta 1992.

El repertorio alfabético de palabras lexicalizadas con morfemas apreciativos en el CorpLO/LE está compuesto por 101 unidades. A continuación ofrecemos una lista de todas ellas en singular; solo se anotan en plural cuando tienen un significado propio en este número ( $c a-$ sillas, juntillas, palomitas...). Además, añadimos en notas detalles que no podemos obviar por su pertinencia. Comentamos entre comillas simples una acepción concreta si atañe en exclusiva a la palabra documentada y, por tanto, las fechas corresponden a este significado. Asimismo, anotamos varios datos de interés entre paréntesis, a saber:

(a) El vocablo base (primero según el diccionario de Corominas y Pascual, y separado por una barra oblicua, según el $D L E$; si coinciden ambas referencias, solo aparece una vez). Anotamos una $d$ (seguida de punto) delante del derivante cuando en el $D L E$ se especifica su origen diminutivo. Cuando aparece el símbolo $\varnothing$, indica que la palabra no se registra en ninguno de los dos diccionarios.

(b) El primer año de registro en el CORDE y, entre corchetes, el año en que aparece por primera vez en los diccionarios académicos.

8 La categoría de los términos habría sido un factor de análisis interesante, pero al no haber encontrado en el Corp-LO/LE palabras lexicalizadas no nominales (a excepción de juntillas) resulta un factor nulo.

9 Corpus de la RAE y ASALE que recoge textos desde los inicios del idioma hasta 1974. 
altillo (d. alto, 1490 [1770])

banquillo (Ø/d. banco, 1493 [1726])

bizcochuelo (d. bizcocho, 1929 [1726])

bocadito (Ø/d. bocado, 1605 [1726-1989])

bolillo (bola/d. bolo, 1535 [1726])

boniatillo (Ø, Ø [1914])

botiquín (d. botica, 1596 [1726])

cabecilla (d. cabeza, 1605 [1729])

cabrito (cabra/d. cabro, 1200 [1729])

cafetín (Ø, 1878 [1884])

camarín (d. cámara, 1577 [1729])

canillita (canilla, 1935 [1970]

capacillo 'recipiente de papel, similar a un cucurucho' (Puerto Rico) (Ø, Ø [Ø])

carretilla (carretera/ d. carreta, 1490 [1729])

casillas $^{14}$ (d. casa, 1545 [1791])

cebolleta (cebolla/Ø, 1513 [1729])

cebollino (cebolla/Ø, 1269 [1729])

cigarrillo (¿/Ø, 1748 [1884])

comodin (cómodo, 1832 [1822])

costilla (cuesta/costa, 1240-1250 [1780])

cuartilla (cuartel/d. cuarta, 1462 [1817]) avanzadilla (Ø/avanzada, 1868 [1983])

barrilete (d. barril, 1490 [1726])

bocadillo (boca/d. bocado, 1409 [1726])

bolilla (Ø, 1889 [1983])

bolsillo (bolsa/d. bolso, 1550 [1726])

boquete (boca ${ }^{10}, 1764$ [1726])

botin (bota, 1527 [1726])

cabecita $\left(\varnothing, 1935\left[\varnothing^{11}\right]\right)$

cacillo (Ø, 1600 [1780])

camarilla 'conjunto de personas que influyen subrepticiamente en los asuntos de Estado o en las decisiones de alguna autoridad superior' (d. cámara, $1821[1869]^{12}$ )

canalillo 'comienzo de la concavidad que separa los pechos de la mujer tal como se muestra desde el escote' (Ø/d. canal, Ø [2014])

cantaleta (cantar, 1598 [1729])

carrerilla (d. carrera, 1605 [1729])

carrillo $\left(\oslash^{13}, 1240\right.$ [1729])

casquete (casco, 1270 [1729])

cebollín 'cebollino' (México, El Salvador, Colombia, Venezuela, Bolivia, Chile) (Ø)

cerillo (cera/Ø, 1818 [1925])

coletilla (cola/Ø, 1758 [1780])

conventillo 'casa de vecindad' (convento/ $\emptyset^{15}$, 1853 [1927])

cuadrilla (cuadra/ cuadro, 1284-1295 [1817])

escalerilla (escalera/Ø, 1514 [1732])

10 En la primera edición de la RAE donde aparece la palabra (1726), se dice que "[e]s como diminutivo de boquerón'. Explicación etimológica que se eliminó en las ediciones posteriores.

11 En los diccionarios de la RAE no se documenta la palabra cabecita con la acepción que tiene en Argentina para designar a determinadas personas de la clase trabajadora, identificadas por el color oscuro de su pelo y piel.

12 Para camarilla como 'estancia', acepción con la que no aparece en el Corp-LO/LE ni tampoco en el $D L E$, las fechas serían otras: 1402 [1729].

13 Aunque ambos diccionarios aluden a su origen incierto, Corominas y Pascual lanzan dos hipótesis: puede ser un diminutivo de carro o un derivado de cara.

14 En la edición de 1729, casillas aparece compartiendo entrada con casica. De 1780 a 1884, también los acompaña casita.

15 Desde 1780, la RAE recoge conventillo como '[1]a casa de viviendas pequeñas, en las que suelen habitar mujeres perdidas y hombres viciosos'. Respecto del sentido que tiene en el Corp-LO/LE, resulta más preciso '[c]asa antigua, en general con un gran patio interior, cuyas habitaciones se alquilan a numerosas familias que comparten el baño y la cocina' (zonas andina, rioplatense y chilena, Dic Am). 
espejuelo (d. espejo, 1422-1425 [1732])

estribillo (d. estribo, 1535 [1732])

galletita $(\varnothing)$

gatillo (d. gato, 1493-1564 [1734])

habichuela (d. haba, 1754 [1734])

historieta (d. historia, 1729 [1803])

liguilla 'competición deportiva' (liga/Ø, Ø [1984' $\left.{ }^{16}\right]$ )

mantequilla (manteca/Ø, 1467 [1803])

mascarilla (máscara/Ø, 1599 [1734])

mirilla (d. mira, 1835 [1899])

olivillo (d. olivo, 1962 [1899])

palmito (palma, 1423 [1737])

pandilla (pando/panda, 1419-1426 [1737])

papeleta (papel/ papel y -eta, 1578 [1737])

pasillo (Ø/ d. paso, 1538 [1780])

pelillos (d. pelo, pelillos a la mar 1605 [1803])

pepinillo (Ø, 1275 [1822])

picadillo (d. picado, 1580-1627 [1737])

planilla (Ø/d. plana, 1775 [1984])

platillo I (d. plato, comunicar a bombo y platillo 1956 [1822])

puntilla (punto/d. punta, 1438 [1737])

redecilla (red/Ø, 1492 [1737])

señorito (d. señor, 1565 [1739])

solomillo (lomo/ d. solomo, 1565 [1739]) estampilla (estampar/d. estampa, 1634 [1732])

frutilla (d. fruta, 1527-1555 [1732])

ganchillo (gancho/Ø, 1893 [1803])

guerrilla (d. guerra, 1527 [1734])

hatillo (d. hato, 1480-1490 [1803])

juntillas (1545 [Ø])

maletín (d. maleta, 1876-1880 [1869])

mantilla (manta/d. manto, 1477-1491 [1734])

mercadillo (Ø, 1519-1526 [1984 $\left.\left.{ }^{17}\right]\right)$

mundillo 'conjunto limitado de personas que tienen una misma posición social, profesión o quehacer' (d. mundo, 1869 [1984])

palacete (Ø ${ }^{18}, 1897$ [1947])

palomitas (d. paloma, 1972 [1927])

pantorrilla (¿?/pantorra ${ }^{19}, 1445-1519$ [1737])

parrilla (parra, 1400 [1737])

patitas (pata/Ø, poner de patitas en la calle $\left.1604[1992]^{20}\right)$

peluquín (peluca/Ø, 1727 [1737])

pesadilla (d. pesada, 1429 [1737])

pitillo 'cigarrillo' (d. pito, 1847 [1914])

plantilla (d. planta, 1513 [1737])

platillo II 'alimento que se sirve en un plato'

(Nicaragua y México) (d. plato, 1552 [2010])

rabillo (d. rabo, 1521 [1803])

señorita (d. señor, 1495 [1899])

sillin (d. silla, 1889 [1884])

taquilla 'armario' (d. taca, 1800 [1884])

16 El significado de 'cinta o liga angosta o estrecha' se registra en los diccionarios desde 1803.

17 En el Tesoro solo aparece en las ediciones de 1984 y 1989.

18 Sorprende que el $D L E$ no ofrezca un paréntesis etimológico en la entrada palacete cuando las Academias, al hablar de los diminutivos transparentes y opacos, sostienen que «todo hablante reconoce la relación que existe entre palacete y palacio" (RAE y ASALE 2009: 636).

19 Corominas y Pascual (1981: 376) rechazan la etimología pantorra y proponen justamente la contraria: "No nos aclara mucho las cosas saber que en la Montaña y alguna vez en otros puntos de Castilla (Cabrera), así como en Méjico (R. Duarte), se dice pantorra por pantorrilla, pues aquella forma, lejos de ser antecedente de esta, parece más bien un derivado regresivo".

20 Las fechas corresponden al registro de la locución verbal en el Corp-LO/LE. 
teresina 'moto scooter' (Puerto Rico) (Ø)

tocineta (tocino/Ø, $1891[\varnothing]$ )

trompetilla (trompeta/Ø, 1527-1561 [1739])

varilla (d. vara, 1400 [1739])

veranito $^{22}(\varnothing, 1871$ [1803-1869])

zapatilla (zapato/zapata, 1528 [1739]) terruño (tierra/Ø, 1381-1418 [1739])

tortilla (d. torta, 1400-1421 [1739])

vainilla (d. vaina, 1494 [1739])

ventanilla $^{21}$ (d. ventana, 1498 [1739])

zancadilla (d. zancada, 1487 [1739])

Un elevado número de estas palabras lexicalizadas, el 92,9 \%, aparece recogido en el $D L E$, frente al $7 \%$ excluido. La mayor parte de ellas fue incorporada en los primeros diccionarios de la RAE (primera mitad del siglo XVIII), como se observa en el gráfico 2.

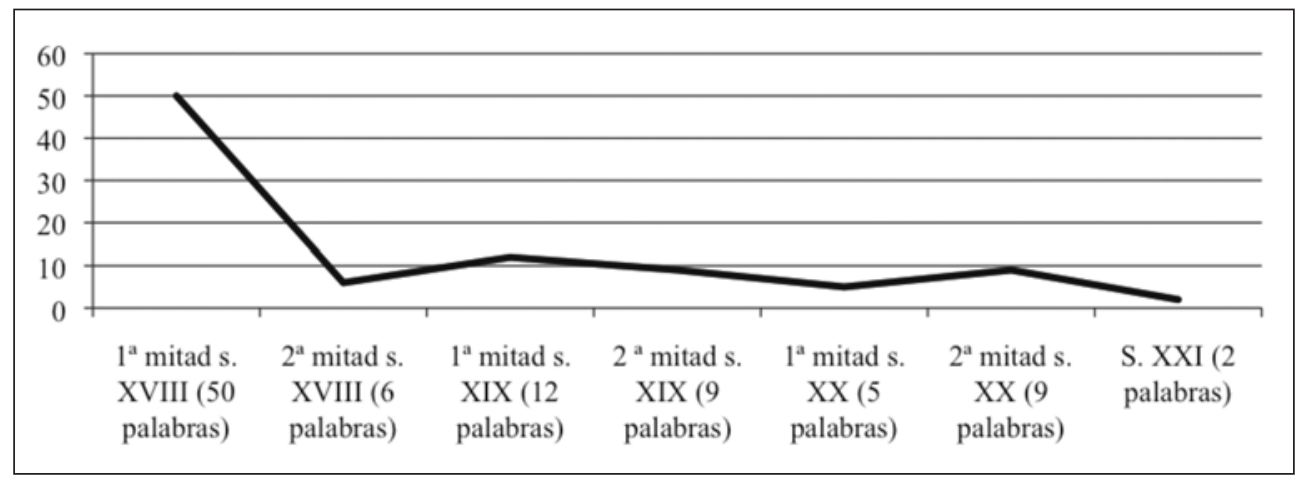

Gráfico 2. Períodos de incorporación de palabras lexicalizadas de nuestros corpus en los diccionarios académicos

Parece evidente que las sucesivas ediciones de los diccionarios académicos han sido bastante menos receptivas a este tipo de vocablos. Tal intuición crece cuando se rastrean las primeras ocurrencias de estas palabras en el CORDE y se comparan los datos de los gráficos 2 y 3 .

Ante todo, debemos alertar de que el CORDE no cuenta con el mismo volumen de textos para cada siglo, por lo que la lectura que puede inferirse del gráfico 2, aunque refleja tendencias, debe tomarse con cierta prudencia. De cualquier modo, parece confirmar que la mayor parte de las palabras lexicalizadas que hoy usamos culminó su proceso de cambio en épocas precedentes al Diccionario de autoridades.

21 Desde 1739 hasta 1899 ventanilla comparte entrada con ventanica. En estas ediciones se dice que es una 'ventana pequeña' (1739) y diminutivo de ventana. Solo en 1925 se incluyen las acepciones con las que hoy conocemos la palabra.

22 La edición de 1869 del diccionario de la RAE distinguía entre veranico, con la acepción que hoy tiene veranillo ('tiempo de calor fuera del estío'), y veranillo, -ito, en el que se anotaba únicamente que era un diminutivo de verano. Corominas y Pascual (1981: 779) recogen solo veranillo y veranico con el sintagma de San Martín: 'en España, tiempo breve durante el otoño en que hace calor'. 


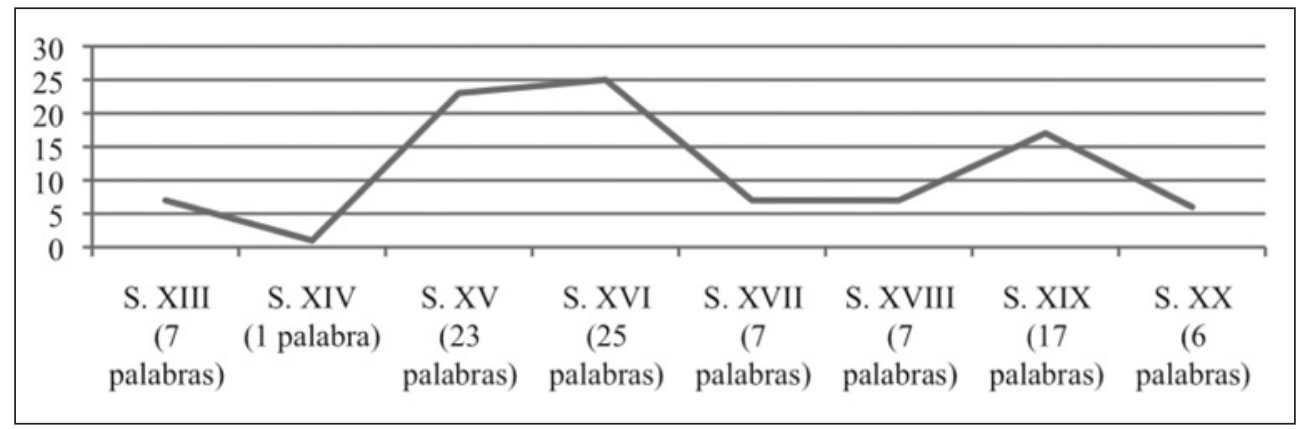

Gráfico 3. Siglo de documentación de las palabras lexicalizadas en el CORDE

La demora en la aceptación del cambio lingüístico es llamativa en los casos de canillita, planilla, platillo II, cacillo, cigarrillo, hatillo, mantequilla, altillo, costilla, cuadrilla y cuartilla. Mientras que para cacillo, cigarrillo, hatillo y mantequilla, su similitud denotativa con la palabra de la que derivan demoró seguramente su aceptación, las razones para los tres primeros pueden ser otras. Canillita, planilla y platillo II son de uso exclusivo americano. Hemos de reconocer que el $83 \%$ de los diminutivos lexicalizados recogidos en nuestro corpus tiene acepciones americanas y, aunque estos puedan tener entradas propias en el $D L E$, la mayoría de ellas no aparece. Aunque tenemos en cuenta que, como advierte Marimón Llorca (2006), en el español de América "lo que venimos a denominar época colonial -entendida como el amplio período que comprende desde el momento mismo de la conquista, en 1492, hasta finales del siglo XVIII- puede considerarse como una etapa fundamental en la evolución del idioma y muy explicativa de su situación presente", los procesos de lexicalización continuaron en épocas posteriores, por lo que la reacción académica resulta tímida. Hemos de reconocer que no encontramos explicación para la tardanza en registrar altillo, costilla, cuadrilla o cuartilla.

Del actual $D L E$ han quedado excluidas cabecita, capacillos, patita y teresina; a las que añadimos algunas otras cuyas entradas remiten a otros vocablos (cebollín a cebolla, galletita a galleta, señorito a señorita). Consideramos cuasi excluidas estas últimas pues no son las preferidas y recomendadas por las Academias, como advierten en sus comentarios sobre el uso de las remisiones entre entradas (3.2. Variantes preferidas); es más, el hecho de considerarlas "variantes" hace suponer que no se les reconoce suficiente independencia lingüística.

Las ausencias pueden deberse a que la vocación panhispánica del $D L E$ no es a veces todo lo consecuente que se espera. Muchas de las palabras comentadas en el párrafo anterior solo aparecen documentadas en las áreas americanas del Corp-LO/LE, como cabecita, capacillo, galletita, teresina, veranito. También muestra falta de coherencia el tratamiento a casos de remisiones como el de avanzadilla, cebollín y cigarrillo, palabras de uso extendido, como demuestran los datos del CORPES.

En el $D L E$ las anotaciones de carácter etimológico superan el $73 \%$ en las palabras lexicalizadas con diminutivo del Corp-LO/LE. El 26,4 \%, sin embargo, no cuenta con esta relevante información. Ello podría explicarse por su origen incierto, pero solo tenemos un caso en esta situación: carrillo; en otros su origen parece evidente, a saber, boniatillo, cacillo, cafetín, cebolleta, cebollino, cigarrillo, coletilla, conventillo, escalerilla, ganchillo, 
liguilla, mantequilla, mascarilla, mercadillo, peluquín, pepinillo, redecilla, terruño, tocineta o trompetilla. Resulta desconcertante que los paréntesis etimológicos desaparezcan a partir de una determinada edición del diccionario académico (de 1780 a 1914 cacillo tuvo la especificación "diminutivo de 'cazo") o sean intermitentes (mantequilla contó con esta información en 1803, 1843, 1869, 1956, pero desaparece en 1832, 1855, 1950, 2014). Asimismo, existen vocablos que compartieron entrada con otras variantes diminutivas de manera irregular, como es el caso de conventillo, que en las ediciones de 1832 a 1927 del diccionario académico apareció junto a conventico y conventito. Igualmente pepinillo se presentó con pepinico y pepinito desde 1822 hasta 1984, y su paréntesis etimológico de 'diminutivo de pepino' se mantuvo hasta el $D L E^{23}$.

Mirando con más detalle las anotaciones de los artículos del $D L E$, podemos comprobar que, aunque la mayoría de los vocablos cuente con entrada propia y paréntesis etimológico, un $16 \%$ carece de aclaración sobre su origen diminutivo, aun en casos tan evidentes como el de botín y canillita. Es cierto que en algunos de ellos el origen diminutivo es dudoso (boquete, cantaleta, casquete, costilla, pantorrilla, papeleta).

El análisis de los cambios semánticos de los diminutivos lexicalizados es un aspecto especialmente interesante pues son el origen de su evolución hacia la independencia léxica. Observamos en ellos si habían experimentado un cambio de significado en relación con el vocablo del que derivaban y en qué grado, tarea en la que el $D L E$ y el DicAm fueron eficaces herramientas de consulta.

La complejidad del análisis hizo necesario crear una tipología sencilla pero efectiva, basada en el grado o intensidad de la liaison semántica entre el diminutivo lexicalizado y su palabra base según la cantidad de acepciones compartidas. Así, consideramos un cambio de significado profundo (del tipo I en la clasificación posterior) cuando el diminutivo lexicalizado designa una realidad nueva, independiente - excluyendo el sentido metafórico- de la referida por la palabra base. Este es el caso de estribillo, que tiene un significado sustancialmente diferente a estribo; pero no lo es el de pandilla, pues no difiere en esencia de panda, su palabra base.

Nuestro repertorio de diminutivos lexicalizados queda sistematizado en tipos I, II y III, según cumplen los siguientes criterios básicos:

I. La palabra base y la lexicalizada no comparten ninguna acepción: banquillo, bolilla, bolillo, boniatillo, botiquín, cabecita, camarilla, canalillo, cantaleta, capacillo, carrerilla, carrillo, cebolleta, cebollín, cebollino, cerillo, conventillo, costilla ${ }^{24}$, cuadrilla, cuartilla, espejuelo, estampilla, estribillo, frutilla, gatillo, guerrilla, historieta, liguilla, maletín, mantilla, mascarilla, mirilla, mundillo, olivillo, palacete, palmito, palomitas, papeleta, parrilla, pelillos, pepinillo, pesadilla 25 , picadillo, pitillo, planilla, plantilla, puntilla, redecilla, señorita, señorito, sillín, taquilla, teresina, trompetilla, vainilla, ventanilla, zancadilla, zapatilla.

23 Otro caso similar: redecilla comparte entrada con redecica y redecita desde 1837 hasta 1884, fecha de la edición del diccionario de la RAE en que se vuelve únicamente a registrar redecilla (de 1737 a 1837 también aparecía como única entrada).

24 En la entrada de costa, el $D L E$ remite a costilla, pero se señala que es una acepción en desuso.

25 El DLE registra las acepciones de 'ensueño angustioso' y ‘opresión del corazón' en la entrada pesada, pero en desuso. 
II. La palabra base y la lexicalizada comparten alguna (menos del $50 \%$ ) de las acepciones: altillo, barrilete, bocadillo, bocadito, bolsillo, boquete, cabecilla, cabrito, camarín, carretilla, casillas, casquete, comodin, mantequilla, pasillo, peluquín, platillo, rabillo, tortilla, varilla.

III. La palabra base y la lexicalizada comparten el $50 \%$ o más de las acepciones: avanzadilla, bizcochuelo, botín, cacillo, cafetín, canillita ${ }^{26}$, cigarrillo, coletilla, escalerilla, galletita, ganchillo, habichuela, hatillo, juntillas, mercadillo, pandilla, pantorrilla, patitas, solomillo, terruño.

La mayor parte de los diminutivos lexicalizados del Corp-LO/LE (59,2\%) es hoy, por tanto, independiente semánticamente de su base derivativa (tipo I). Alrededor de un 20,4\% tiene alguna acepción igual o similar que su término base (tipo II), y también un 20,4 \% no difiere, en esencia, de su étimo (tipo III).

Al tratarse de diminutivos en su forma, analizamos si la denotación de pequeñez está o estuvo contenida en las acepciones de nuestras palabras lexicalizadas. Como resultado, obtuvimos también una clasificación tripartita que pasamos a exponer con ciertos datos interesantes: por una parte, en la clase (2), reflejamos entre paréntesis, con un signo de menos delante, el año en el que la RAE elimina el matiz de aminoración; y por otra, en (1) y (2), anotamos entre paréntesis, con un signo de más delante, las fechas que enmarcan el periodo en el que sí aparece el rasgo, siempre y cuando sea posterior a la edición primigenia de registro (que puede consultarse para cada palabra al principio de este apartado).

(1) Palabras que tienen acepciones con designaciones diminutivas: avanzadilla, bolilla, bolillo, cabecita ${ }^{27}$, cabrito, cacillo, camarín, casillas, casquete, carretilla, cigarrillo (+1925-2014), galletita, guerrilla, liguilla, maletín, mascarilla, palacete, pepinillo, peluquín, señorito, sillín.

(2) Palabras que tuvieron (ya no) acepciones con designaciones diminutivas: banquillo (-1770), bizcochuelo (-1770) bocadillo (-1770), bolsillo (-1770), botiquín (-1914), cabecilla (-1780) carrerilla (-1780), cebolleta (-1899), cebollino $(+1780-1899)$, escalerilla (-1780), estampilla (-1780), frutilla (-1780), ganchillo (+1803-1869), gatillo (-1780), espejuelo (-1780), mercadillo (+1984-1989), pelillo (1780), pitillo (-1780), plantilla (-1780), platillo (-1780), puntilla (-1780), rabillo $(-1832)$, redecilla $(-1780)$, solomillo (1843), terruño (+1992-2014), tortilla (-1780), trompetilla (-1780), varilla $(-1780)$, ventanilla $(-1780)$, zapatilla $(-1780)$.

(3) Palabras que nunca han tenido acepciones con designaciones diminutivas: altillo, barrilete, boniatillo, boquete, botín, cafetín, camarilla ${ }^{28}$, canalillo, canillita, cantaleta, capacillo ${ }^{29}$, carrillo, cebollín, cerillo, coletilla, conventillo, costilla, comodín, cuadrilla, cuartilla, estribillo, hatillo, historieta, juntillas, mantequilla, mantilla,

26 Establecemos la comparación con las acepciones de canilla en el DicAm.

27 Aunque la palabra con el sentido rioplatense no se registra como diminutivo en el $D L E$ ni en el DicAm, entendemos que la expresión americana cabecita negra se vale del diminutivo para señalar la pequeña dimensión de la cabeza del ave (Carduelidae; Carduelis magellanica).

28 Camarilla tuvo una designación diminutiva con la acepción de 'estancia' en la edición de 1729, pero esta se eliminó en la de 1780 .

29 Incluimos capacillo, cebollín y teresina en este apartado teniendo en cuenta únicamente la acepción con la que aparecieron en nuestro corpus caribeño, citada junto a las palabras al inicio de este apartado. 
mirilla, mundillo, olivillo, palmito, palomitas, pandilla, pantorrilla, papeleta, parrilla, pasillo, patitas, pelillos, pesadilla, picadillo, planilla, señorita, taquilla, teresina, vainilla, veranito, zancadilla.

Es posible que los diminutivos lexicalizados anteriores tengan aún la capacidad de connotar de una manera similar a como lo hacen los vocablos transparentes con sufijos apreciativos. Piénsese, por ejemplo, en el carácter afectivo, cortés o persuasivo que puede tener el término mundillo. Ahora bien, que estas connotaciones sigan operando indica que la palabra todavía no ha culminado su proceso de lexicalización y casi siempre convive con su palabra base con similares o iguales acepciones. Sin embargo, las denotaciones diminutivas (la dimensional y la aminorativa) pueden mantenerse en el término lexicalizado hasta el término de su lexicalización, como ocurre, por ejemplo, con cacillo y el resto de las palabras que aparecen en el grupo de las que tienen acepciones con designaciones diminutivas (1) precedente $(21,4 \%$ respecto de los otros dos grupos).

Resulta interesante comprobar que casi la mitad de los vocablos (48 \%) nunca fue definida con una acepción aminorativa en los diccionarios académicos (grupo 3, palabras que nunca han tenido acepciones con designaciones diminutivas); mientras, algunos perdieron sus denotaciones diminutivas con el tiempo (grupo de palabras que tuvieron (ya no) acepciones con designaciones diminutivas (2), más del $30 \%$ ). En las primeras ediciones de estos diccionarios (primera mitad del siglo XVIII), era común encontrar la palabra lexicalizada con alguna acepción que contuviera algo relacionado con lo pequeño o la aminoración. Hacia el último cuarto del mismo siglo, se eliminan estas alusiones, tal vez porque la palabra dejó de denotar disminución o porque se consideró improcedente explicitarlo. Llama la atención que, dentro del grupo (2), 22 de los 30 términos clasificados perdieron sus acepciones diminutivas en 1770 o 1780 .

\section{VARIEDADES DEL ESPAÑOL Y DIMINUTIVOS LEXICALIZADOS EN EL CORP-LO/LE}

En cuanto a la extensión de los diminutivos lexicalizados, y tras la detallada consulta del Corpus de referencia del español actual (CREA) y el Corpus del español del siglo XXI (CORPES), pudimos comprobar que la mayor parte de ellos (74,5\%) se documenta en todas las variedades de español con la misma acepción, por lo que pueden considerarse de uso panhispánico con independencia de la procedencia geolectal del documento y del hablante donde hubiera sido localizado en nuestro corpus. Otras palabras tenían una vitalidad más restringida: el 16,3 \% apareció en más de una variedad con la misma acepción (bizcochuelo, bolilla, canillita, cantaleta, carrerilla, cebolleta, cebollín, cebollino, cerillo, coletilla, conventillo, espejuelo, frutilla, olivillo, platillo, trompetilla y veranito) y el 9,2\% era exclusivo de una determinada área lingüística (boniatillo, capacillo y teresina del Caribe; canalillo, cacillo y solomillo ${ }^{30}$ de España; cabecita y galletita del Río de la Plata).

Sobre la mayoría panhispánica antes señalada, debemos precisar que el DicAm registra diferentes acepciones americanas, no válidas para las variedades europeas del español en un $71,4 \%$ de las palabras del Corp-LO/LE.

30 Solomillo puede encontrarse en las variedades americanas de forma muy esporádica; en Colombia se prefiere solomito (DicAm), forma no documentada en el Corp-LO/LE. 
Como podemos observar en los gráficos 4 y 5, las palabras lexicalizadas (159) en el Corp-LO/LE tienen un porcentaje de uso mucho menor que las palabras en diminutivo pero sin lexicalizar (611) en todas las áreas lingüísticas. Esta diferencia se acentúa en el corpus oral, donde solo se documentan 33 diminutivos lexicalizados, tal vez por el uso reiterado (excesivo en comparación con otras situaciones) del diminutivo apreciativo en los programas de cocina con motivos moduladores del discurso hacia la familiaridad, la cercanía y la intimidad.

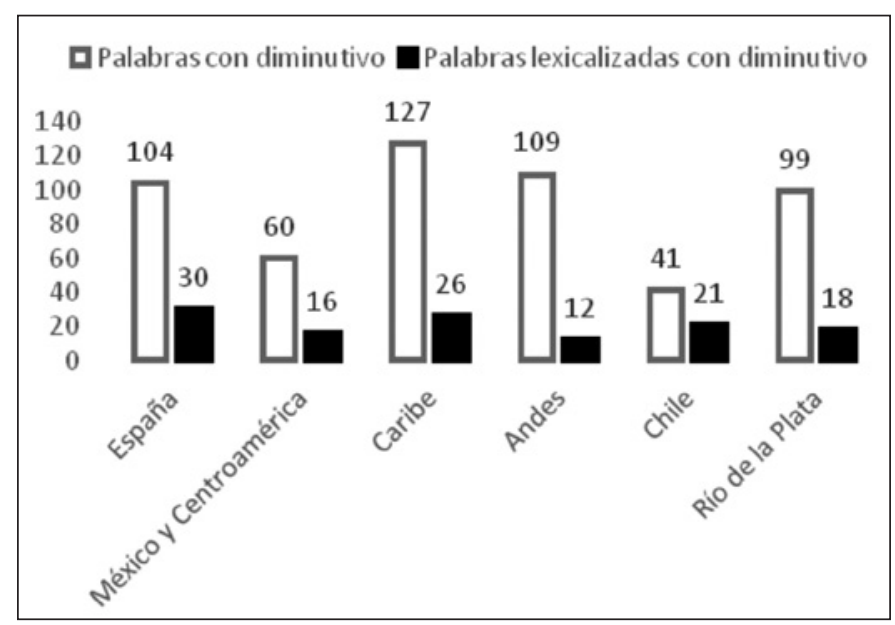

Gráfico 4. Relación del número de palabras con diminutivo y el número de palabras lexicalizadas con diminutivo en las variedades de español (Corp-LE)

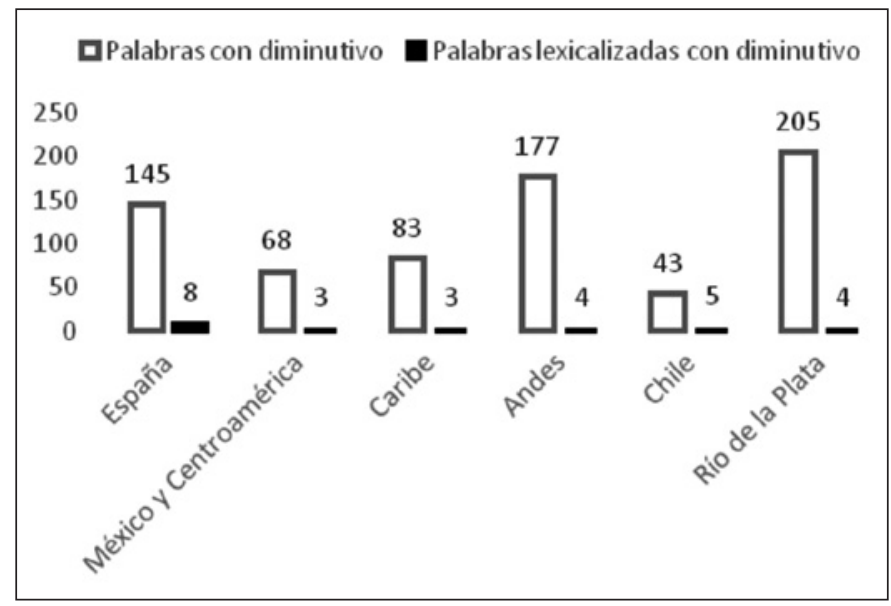

Gráfico 5. Relación del número de palabras con diminutivo y el número de palabras lexicalizadas con diminutivo en las variedades de español (Corp-LO) 
En los dos corpus, oral y escrito, la zona lingüística más prolija en el uso de diminutivos lexicalizados fue, como aparece reflejado en los gráficos 4 y 5, España (30 palabras en el Corp-LE y 8 en el Corp-LO). A partir de estas cifras, todas las zonas acumulan números más bajos, mayores siempre en el corpus escrito: México-Centroamérica, 16 y 3 respectivamente; Caribe, 26 y 3; Andes, 12 y 4; Chile, 21 y 5; Río de la Plata, 18 y 4.

Respecto de la diversa morfología del diminutivo lexicalizado y las ocurrencias del Corp-LO/LE en las variedades del español, sus formas no se dan en todas las zonas. La mayoría global de -illo, -illa (70 \%) se impone en cada una de ellas, seguida -de lejos- por -ito, -ita, como puede verse en el gráfico 6 . Aunque no hay ninguna forma que esté ausente en todas las zonas, -uño, -uña y -uelo, -uela son poco frecuentes: una ocurrencia en Chile para la primera, y dos y una en el Caribe y Río de la Plata, respectivamente, para la segunda.

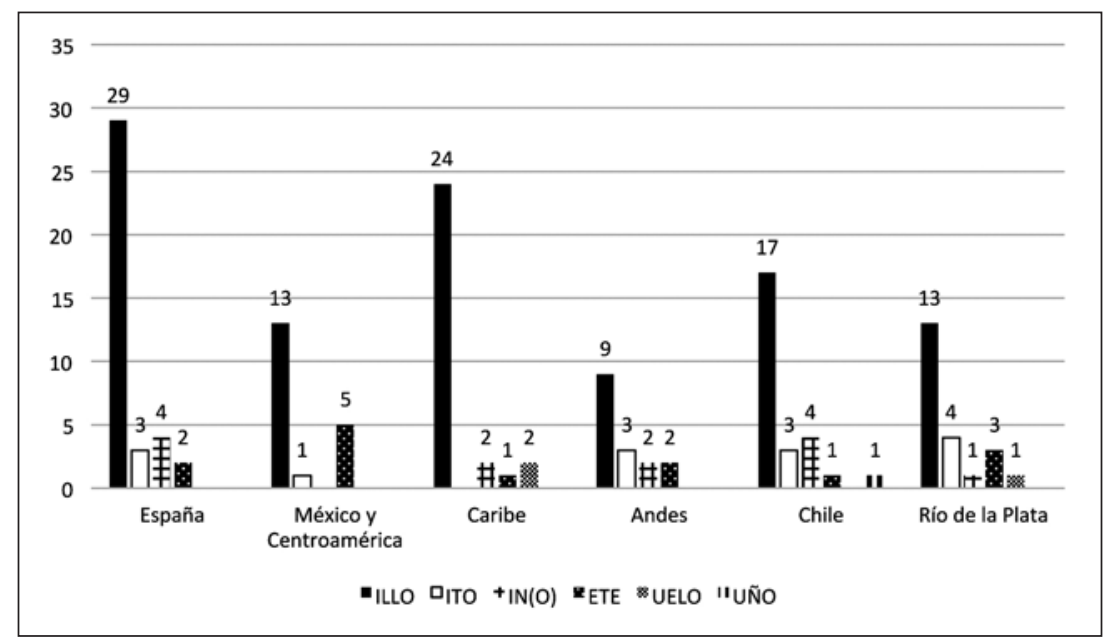

Gráfico 6. Formas diminutivas en palabras lexicalizadas del Corp-LO/LE por variedades del español

\section{CONCLUSIONES}

El estudio de la lexicalización en dos corpus originales, oral (6 horas y media de grabaciones de programas de cocina) y escrito (970 artículos de prensa), nos ha permitido observar el estado de este fenómeno en los diminutivos y su comportamiento en un ámbito panhispánico en el que contamos con la presencia de seis variedades geolectales del español.

El análisis morfológico de las formas recogidas nos permite concluir que en el Cop-LO/ LE está presente un buen número de los morfemas diminutivos propios: -ito, -ita; -illo, -illa; -ete, -eta; -ino, -ina; -uño, -uña, -uelo, -uela, -ín, entre los que destaca el uso de -illo, -illa. Ello puede observarse en el extenso repertorio aportado (101 palabras), donde resultan pertinentes las muchas y diversas anotaciones realizadas, especialmente las del vocablo base según aparece en diferentes diccionarios, así como el primer año de registro en el CORDE y el año en que lo recogen por primera vez los diccionarios académicos. 
Comprobamos que los diccionarios generales han atendido los diminutivos lexicalizados de manera muy desigual. Al respecto, concluimos que el tratamiento de las palabras lexicalizadas con diminutivo en el $D L E$ es dispar en cuanto a tres parámetros: entrada propia, étimo y procedencia diminutiva. El carácter gradual del paso de la pura 'apreciación' (i.e. de ser un diminutivo genuino) a la lexicalización dificulta mantener uniformidad de criterios para su procesamiento en el diccionario.

Este hecho se manifiesta en algunos ejemplos analizados, como el término cebollín, que está excluido del diccionario aun estando extendido por todas las variedades americanas; el vocablo conventillo, que aparece sin étimo aun habiendo sido presentado en ediciones anteriores del diccionario junto a otras variaciones diminutivas de "convento"; o la palabra canillita, cuyo paréntesis etimológico carece de especificación de su procedencia diminutiva. Por otro lado, aunque es posible que la lexicalización diminutiva haya sido un proceso más productivo en épocas precedentes del idioma (probablemente los siglos XV y XVI), hoy es un fenómeno vigente y panhispánico, como lo prueba la incorporación en ediciones recientes del DRAE/DLE de las palabras canalillo (2014), canillita (1970) o palacete (1947).

Tras la múltiple búsqueda realizada podemos concluir que la gran mayoría de los diminutivos documentados en el Corp-LO/LE tiene asentado su proceso de lexicalización ya que un $92,9 \%$ aparece recogido en el $D L E$; muchos de ellos incorporados en los primeros diccionarios de la RAE (primera mitad del siglo XVIII). Llama la atención la tardía aceptación de canillita, planilla, platillo, cacillo, cigarrillo, hatillo, mantequilla, altillo, costilla, cuadrilla y cuartilla, que puede explicarse en algunos casos por la similitud denotativa con la palabra base y su uso exclusivo americano.

La complejidad del repertorio nos inclinó a hacer una doble clasificación de acuerdo con: (a) la distancia semántica entre la palabra base y la lexicalizada, y (b) el grado de retención de la denotación de pequeñez en las acepciones de las palabras lexicalizadas. De la aplicación de la primera pudimos concluir que la mayor parte es semánticamente independiente de su base derivativa (tipo I: 59,2 \%), mientras que el resto de los diminutivos lexicalizados (40,8\%) tiene alguna acepción igual o similar a la de su término base (tipo II: 20,4 \%) o no difiere, en esencia, de su étimo (tipo III: 20,4\%). Y a partir de la segunda clasificación constatamos que casi la mitad de ellos nunca fue definida con una acepción aminorativa en los diccionarios académicos (grupo 3: 48 \%); mientras, algunos perdieron sus denotaciones diminutivas con el tiempo (grupo 2: más del $30 \%$ ).

En general, la lexicalización diminutiva es un fenómeno representativo del carácter esencialmente homogéneo del español. Casi todos los términos se usan en todas las variedades del idioma $(74,5 \%)$ y muy pocos se restringen a una única variedad $(9,2 \%)$. No obstante, si prestamos atención al detalle del factor geolectal, España fue la zona lingüística más prolija (44 formas) en el uso de diminutivos lexicalizados en los dos corpus, oral y escrito, y a partir de ella, las americanas (Caribe, 29; Chile, 26; Río de la Plata, 23; México-Centroamérica, 20; Andes, 17).

Reconocemos que el tema puede -y merece- ampliarse con estudios más detallados, a los que los corpus aportan una fuente veraz y sólida de referencia. Esperamos que los dos corpus presentados, en su diversidad y especificidad, hayan ofrecido datos y reflexiones de interés. 


\section{Referencias bibliográficas}

Ambadiang, T. y B. C. Bergareche (2013). "Aspectos del desarrollo histórico de la alomorfia del diminutivo en español". Formación de palabras y diacronía. Anexo 19 de Revista de Lexicografía. A Coruña; Universidade da Coruña, pp. 172-185.

Asociación de Academias de la Lengua Española (ASALE) (2004). Diccionario de americanismos. Madrid: Santillana: http://asale.org. (Consultado del 18-08-2016 al 14-11-2016).

Bello, A. (1984 [1847]). Gramática de la lengua castellana. Madrid: Edaf.

Brinton, L. y E. Closs Traugot (2005). Lexicalization and Language Change. Cambridge; Cambridge University Press.

Buenafuentes de la Mata, C. y C. Sánchez Lancis (2012). "Procesos de gramaticalización y lexicalización a la luz de los corpus académicos". En Jiménez, T. et alii (eds.). Cum corde et in nova grammatica. Estudios ofrecidos a Guillermo Rojo. Santiago de Compostela: Universidad de Santiago de Compostela, pp. 153-165.

Corominas, J. y J. A. Pascual (1981). Diccionario crítico etimológico castellano e hispánico. Madrid: Gredos.

Cruz Piñol, M. (2012). Lingüística de corpus y enseñanza del español como 2/L. Madrid: Arco/Libros.

Elvira, J. (2006). “Aproximación al concepto de lexicalización”. En Rodríguez Molina, J. y D. M. Sáez Rivera (eds.). Diacronía, lengua española y lingüística. Madrid: Síntesis, pp. 21-41.

Gómez Torrego, L. (2005 [1997]). Gramática didáctica del español. Madrid: Editorial S. M.

Henríquez Ureña, P. (1993 [1921]). “Observaciones sobre el español de América”. En Moreno Fernández, F. La división dialectal del español de América. Alcalá de Henares: Universidad de Alcalá, pp. 39-62.

Kennedy, G. (1998). An Introduction to Corpus Linguistics. London: Longman.

Kock, J. de (ed.) (2001). Lingüistica con corpus. Catorce aplicaciones sobre el español. Salamanca: Universidad de Salamanca.

Lang, M. F. (2002). Formación de palabras en español. Morfología derivativa productiva en el léxico moderno. Madrid: Cátedra.

Lázaro Mora, F. (1977). "Morfología de los sufijos diminutivos -ito (a), -ico (a), -illo (a)", Verba, 4, pp. 115-125: http://dspace.usc.es/bitstream/10347/3132/1/pg_117-128_verba4.pdf (20-112015).

Lázaro Mora, F. (1999). "La derivación apreciativa". En Demonte, V. e I. Bosque (coords.). Gramática descriptiva de la lengua española. Madrid: Espasa, pp. 4646-4684.

Marcos Marín, F. y P. España Ramírez (2001). Guía de gramática de la lengua española. Madrid: Espasa Calpe.

Marimón Llorca, C. (2006). El español en América: de la conquista a la Época Colonial. Alicante: Biblioteca Virtual Miguel de Cervantes: http://www.cervantesvirtual.com/obra-visor/el-espaolen-amrica-de-la-conquista-a-la-poca-colonial-0/html/00f4b922-82b2-11df-acc7-002185ce6064_2. html (24-04-2017).

Martín Camacho, J. C. (2001). "Sobre los supuestos diminutivos infijados del español”, Anuario de Estudios Filológicos, 24, pp. 339-351.

Malkiel, Y. (1958). "Los interfijos hispánicos”. En Catalán Menéndez-Pidal, D. (ed.). Miscelánea homenaje a André Martinet II. Madrid: Gredos, pp. 109-199.

Monge, F. (1965 [1962]). "Los diminutivos en español”. En Straka, G. (ed.). Actes du Xe Congrès International de Linguistique et Philologie Romanes. Strasbourg: Klincksieck, París, I, pp. 137-147.

Montero Curiel, P. (2008). "El proceso de lexicalización del diminutivo ardilla", Anuario de estudios filológicos, 31, pp. 117-131.

Navarro, C. (2008). La comunicación especializada. Oxford: Peter Lang Publishing.

Nebrija, A. de (1492). Gramática de la lengua castellana: www.antoniodenebrija.org (23-12-2015). 
Pérez Hernández, M. C. (2002). "Explotación de los córpora textuales informatizados para la creación de bases de datos terminológicas”, Estudios de lingüística del español, 18: http://elies.rediris.es/ elies18/ (20-07-2016).

Pharies, D. (2002). Diccionario etimológico de los sufijos españoles. Madrid: Gredos.

Ponce de León, R. Z. (2006). "Interpretación semántica de los morfemas apreciativos: la noción de disminución dentro de un dominio cognoscitivo", Lingüística Mexicana, 3.1, pp. 51-69.

Real Academia de la Lengua Española (RAE). Banco de datos (CORDE) [en línea]. Corpus diacrónico del español. Versión electrónica: http://www.rae.es (18-08-2016 al 14-11-2016).

Real Academia de la Lengua Española (RAE). Banco de datos (CREA. Versión anotada) [en línea]. Corpus de referencia del español actual: http://www.rae.es. (18-08-2016 al 14-11-2016).

Real Academia de la Lengua Española (RAE). Banco de datos (CORPES XXI) [en línea], Corpus del Español del Siglo XXI (CORPES): http://www.rae.es (18-08-2016 al 14-11-2016).

Real Academia de la Lengua Española (RAE) y Asociación de Academias de la Lengua Española (ASALE) (2001). Nuevo tesoro lexicográfico de la lengua española. Madrid: Espasa Calpe.

Real Academia de la Lengua Española (RAE) y Asociación de Academias de la Lengua Española (ASALE) (2009). Nueva gramática de la lengua española. Madrid: Espasa.

Real Academia de la Lengua Española (RAE) y Asociación de Academias de la Lengua Española (ASALE) (2014). Diccionario de la lengua española, 23. ${ }^{a}$ edición. Madrid: Espasa: http://www. rae.es (18-08-2016 al 14-11-2016).

Sánchez, A. et alii (eds.) (1995). CUMBRE-Corpus lingüístico del español contemporáneo. Madrid: SGEL.

Sánchez Lancis, C. (2015). "El diccionario como corpus de estudio diacrónico: el cambio gramatical en la lexicografía del español". En Bernal, E. y S. Torner (eds.). Relaciones morfológicas y diccionario. A Coruña: Universidade da Coruña, pp. 11-34.

Seco, R. (1971 [1930]). Manual de gramática española. Madrid: Aguiar.

Spitzer, L. (1921). “Arribota”, Revista de Filología Española, 8, pp. 58-60. 